opportunity for a young student to produce a work of absolutely first-class value. It is to be hoped that Dr. Malinowski will be able to publish in full the remainder of his material, which, judging from this sample, will mark a distinct progress in ethnographical research and interpretation,

A. C. HADDoN.

\section{Pure and Applied Electricity.}

(I) Einführung in die Theorie der Elektrizität und des Magnetismus. Zum Gebrauch bei Vorträgen, sowie zum Selbstunterricht. Von Prof. Dr. Max Planck. Pp. v+208. (Leipzig: S. Hirzel, ig2z.) 42 marks. (2) Elettrotecnica elementare con numerosi problemi. By A. Occhialini. Vol. I : Magnetismo-Elettrostatica - Elettrochimica-- Elettrodinamica - Elettromagnetismo-Induzione elettromagnetica. $\mathrm{Pp} . \mathrm{v}+$ 344. (Firenze: Felice Le Monnier, n.d.) n.p.

(3) Installations électriques industrielles: choix du matériel. Par R. Cabaud. Pp. 316. (Paris: J.-B. Bailliere et Fils, 1922.) Io francs.

THE first of these three books discusses the groundcusses the experimental laws and their laboratory applications, and the third is a severely practical work for the commcrical electrician. They are all introductions to the subject, but they are intended for very different classes of readers.

(I) Dr. Max Planck's work is philosophical, and presupposes a knowledge of mathematics and of the mathematical theory of electricity which is possessed by few. The foundations on which the ordinary mathematical equations rest are examined, and particular stress is laid on the units in which they are measured. The Gaussian, the electrostatic, and the electromagnetic systems of units are considered. The work will be very welcome to the pure theorist and will increase his confidence in the soundness of the physical basis of the mathematical theory. The clear distinction made between magnetic force and magnetic induction is very convincing. The experimenter will find little that is directly helpful to him in this book, but he will appreciate, however, the author's method of getting the capacity of an ellipsoid and the deductions that can be made from it.

(2) The second work under notice is very similar to the standard English books on experimental electricity and magnetism. The author's descriptions of the main phenomena are very clear, and the numerous examples given are instructive. A very full discussion is given of the problem of a number of batteries of different electromotive forces and resistances in parallel with one another. A thorough knowledge of this NO. 2762 , VOL. I IO] problem is a great help to students when they come to the corresponding problems of dynamos or alternators running in parallel with one another. The definition given of the temperature coefficient of metals, however, is not sufficiently accurate for modern requirements. The rating of a dynamo depends on its temperature after a run at full load, and the temperature of the coils is computed from their measured resistance and a knowledge of the temperature coefficient of copper. As the problem is one of great commercial importance it is necessary to distinguish between the temperature coefficeint of the volume resistivity, the mass resistivity; and the constant mass resistance. These are all different and vary with the lower of the two temperatures considered. The approximate formulæ for the self-induction of a coil are given, but we think that their limitations should have been stated.

(3) M. Cabaud's book is very general and can be appreciated only by a technical expert. It presupposes a thorough knowledge of practical electrical engineering. In the first section of the book a general discussion is given of the kind of electric machine required to do special work; for example, whether a direct-current or an alternating-current machine will be the more useful. In the latter case also the question of whether it is to be single phase or polyphase is considered. The efficiency of the machine, its heating under load, the electric strength of the insulating wrappings, etc., have all to be considered. In the second section the characteristics of the machines, whether rotating or stationary, are described. In the last section the usefulness of the various characteristics are discussed, and the important question of the best guarantees that should be demanded from the manufacturers is considered.

\section{The Petroleum Industry.}

(I) Encyclopédie Scientifique: Bibliothèque de géologie et de minéralogie appliquées: Les Gisements de pétrole. Par Jean Chautard. Pp. viii +viii $+33^{\circ}$. (Paris: Gaston Doin, 1922.) I4 fr.

(2) The Oil Encyclopedia. By Marcel Mitzakis. Pp. xvi $+55^{\mathrm{r}}$. (London: Chapman and Hall, Ltd., I922.) 2xs. net.

(3) The Economics of Petroleum. By Joseph E. Pogue. Pp. ix +375 . (New York: J. Wiley and Sons, Inc.; London: Chapman and Hall, Ltd., I92 I.) 33s. net.

THE "Encyclopédie Scientifique" constitutes a comparativelynew departure in French technical literature, and has for its scope the ultimate publication of some thousand volumes dealing with the various phases of pure and applied science. M. Jean Chautard's 